\title{
Prevalence of infectious diseases on dairy farms classified on the basis of their biosecurity score
}

\author{
Laura Perillo ${ }^{1}$, Giuseppe Cascone ${ }^{2}$, Francesco Antoci $^{2}$, Giuseppe Piccione ${ }^{1 凶}$, \\ Claudia Giannetto $^{1}$, Rosario Salonia ${ }^{2}$, Felice Salina ${ }^{2}$, Elisabetta Giudice ${ }^{1}$, \\ Vincenzo Monteverde ${ }^{2}$, Francesca Licitra ${ }^{2}$ \\ ${ }^{1}$ Department of Veterinary Science, University of Messina, \\ Polo Universitario dell'Annunziata, 98168, Messina, Italy \\ ${ }^{2}$ Istituto Zooprofilattico Sperimentale della Sicilia “A. Mirri”, 90129, Palermo, Italy \\ gpiccione@unime.it
}

Received: July 9, $2021 \quad$ Accepted: January 31, 2022

\begin{abstract}
Introduction: The aim of the study was to investigate the relationship between biosecurity as scored on the Italian National Animal Welfare Reference Centre (Centro di Referenza Nazionale per il Benessere Animale - CReNBA) checklist and the prevalence of Mycobacterium avium subsp. paratuberculosis, Chlamydophila abortus and Neospora caninum on dairy farms located in Ragusa, Italy. Material and Methods: The checklist was used to assign an animal welfare score to 31 dairy farms. Twenty-one farms with a moderate score $(>33 \%,<66 \%$ ) formed group 1 , and 10 farms with a high score ( $>66 \%)$ were group 2 . Blood samples were collected from all cows on each farm to investigate the titres of antibodies against the relevant pathogens. Two-way analysis of variance was applied to assess differences between the two experimental groups and the Mann-Whitney test was applied to evaluate prevalence differences in the tested parasites between the groups. Results: All tested farms had a score that classified them as either good or excellent. A higher incidence of Neospora caninum was observed in group 1. The incidences of the other two parasites were no different between the two groups. Conclusion: The CReNBA checklist represents an impartial, reproducible, functional and smart instrument based on risk analysis and assigns a farm a mathematical animal welfare score. Among the parasites tested for, only Neospora caninum had prevalence influenced by biosecurity. Our preliminary results highlighted the positive associations between good animal welfare, high levels of biosecurity, and the prevention of the infectious diseases caused by the parasites in our focus, which are common on dairy farms.
\end{abstract}

Keywords: biosecurity, animal welfare, farm animals, dairy cow, infectious diseases.

\section{Introduction}

In many countries, the dairy industry is increasingly focusing on the control of biosecurity and infectious diseases (2). Such diseases are resisted, if resistance is possible in the physiological state, by fully immunocompetent animals which do not have to contend with significant challenges to the immune system. However, on a farm these challenges are manifold and may be from infectious and non-infectious stressors, the effects of which on immunity cannot easily be discriminated and can overlap (16). Stressors are the driving factors in farm animal welfare, and in light of the varied nature of potential stressors, welfare should be viewed as a global condition. Different conditions or factors at the animal level (age, parity, lactation stage, breed, and immune status), as well as at the farm level (housing, nutrition, climate, and management) contribute together to the occurrence of disorders (17). Poor environmental conditions can affect several homeostatic functions and reduce the productive and reproductive performance of livestock. Stress factors and poor welfare can also compromise the animal's immune system and increase its susceptibility to diseases (16). Other relevant risk factors are those related to the calves' feeding management (20). Endemic or epidemic diseases jeopardise livestock production, which directly affects the farmer but also many formal and informal actors in the often complex value chains of animal products. Outbreaks of infections 
with high morbidity and clear clinical signs and/or increased mortality are likely to be recognised by farmers and linked to losses in production. However, endemic infections with less dramatic clinical manifestations such as reproductive disturbances, diarrhea or poor growth may be a part of what farmers perceive as normal and not possible and/or worthwhile to control, despite their negative effects on the farm's income and the region's food security $(17,22)$. Diseases that are endemic need not afflict every farm in a region but can be transmitted from farm to farm if precautions are not adequate. The prevention of the introduction and spread of infectious diseases in animal production is the aim of management practices collectively termed biosecurity. Studies have shown biosecurity to be associated with reduced odds of diseases, improved productivity, and lower use of antimicrobials (8). Risks to the dairy industry can be reduced if dairy farmers proactively respond to specific changes, for instance, by stepping up their efforts to raise biosecurity and cut down the use of antimicrobials and hormones, while concurrently ensuring high standards of animal welfare (4). Improving animal welfare can positively affect numerous aspects of disease resistance and product quality; these consequences have immediate relevance to food safety and quality (5). Biosecurity measures for infectious diseases prevention comprise two major elements: reducing the probability of the introduction of the infectious agent to the farm and reducing the likelihood of its transmission within the herd (12). Among the infectious diseases that can have subclinical manifestations and can be introduced into the herds through infected animals, staff, vehicles or by horizontal transmission, Mycobacterium avium subsp. paratuberculosis, Chlamydophila abortus and Neospora caninum inflict notable economic losses and are the most investigated in the south of Italy $(6,9,18)$.

In 2011, the Istituto Zooprofilattico Sperimentale della Lombardia e dell'Emilia Romagna (IZSLER) developed a draft welfare assessment protocol on dairy farms. This was possible thanks to the aid of the Italian National Animal Welfare Reference Centre (Centro di Referenza Nazionale per il Benessere Animale - CReNBA) and its composition of a checklist. Welfare assessment requires a multidisciplinary approach, and the CReNBA checklist monitors both animal-based measures and nonanimal-based measures on dairy cattle farms. Health is the key component of welfare (e.g. the presence or absence of disease, organ function, metabolic processes, and internal body condition) and is primarily monitored using haematological and biochemical tests (16).

The aim of the present study was to investigate the prevalence of Mycobacterium avium subsp. paratuberculosis, Chlamydophila abortus and Neospora caninum on dairy farms classified on the basis of their biosecurity score in the CReNBA welfare assessment protocol.

\section{Material and Methods}

The study was carried out on 31 high-producing dairy farms located in the province of Ragusa, Italy $\left(36^{\circ} 55^{\prime} 48^{\prime \prime} \mathrm{N}, 14^{\circ} 44^{\prime} 24^{\prime \prime} \mathrm{E}\right.$ and $515 \mathrm{~m}$ above sea level) (Fig. 1), with stocks of a variety of breeds of lactating cows (Italian Friesian, Italian Brown, Red Pied Fleckvieh, Jersey and crossbreeds) aged between 6 months and 12 years.

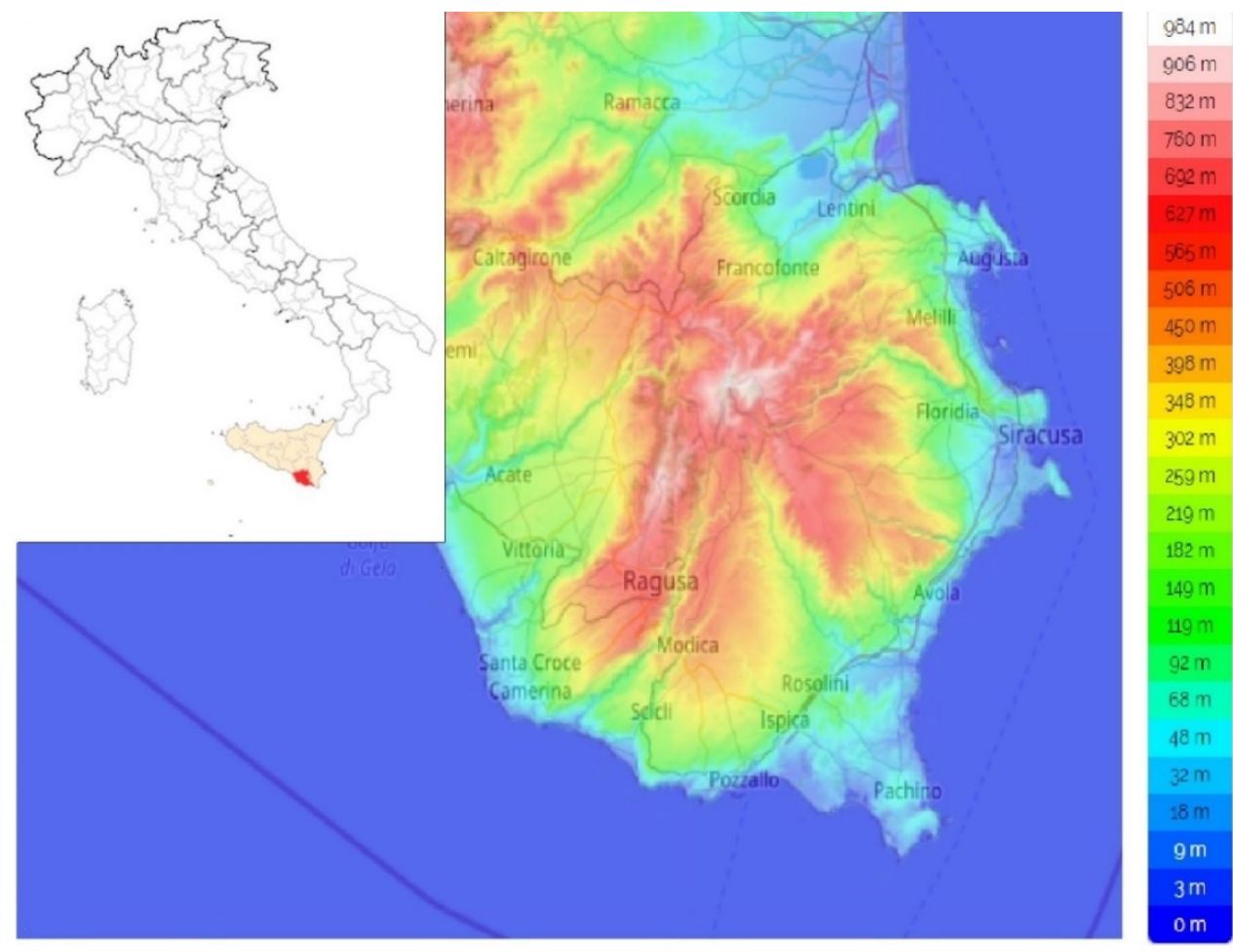

Fig. 1. Map of the province of Ragusa, Italy (36 $55^{\prime} 48^{\prime \prime} \mathrm{N}, 14^{\circ} 44^{\prime} 24^{\prime \prime} \mathrm{E}$ and $515 \mathrm{~m}$ above sea level) 
The herds varied in size from 28 to 418 cows per farm made a total of 2,312 cows and averaged 110.10 head each in group 1, which was a group of farms with good biosecurity and welfare; they varied from 52 to 228 cows per farm, made a total of 1,270 cows and averaged 127 head each in group 2, which was a group of farms with excellent biosecurity and welfare. On all farms, cows were housed in barns with access to a grazing area at least 10 hours a day, and milking was performed twice a day with a milking machine. They were fed a balanced diet daily (fodder, hay and silage), and water was available ad libitum.

The CReNBA method was used for the assessment of the quality of animal welfare maintained on each farm. The checklist provides a $360^{\circ}$ view of the farm by the scores assigned to explicit criteria. The evaluators are qualified veterinarians who take a specific training course. Structural, managerial and biosecurity aspects contribute to determining the final score of the production enterprise, together with the evidence of the animals' ability to adapt to the environment. The checklist is composed of five macro-areas of investigation: A - Farm management and personnel; B Facilities and equipment; $\mathrm{C}$ - Animal-based measures (where the assessment of risk and of the consequent negative effects on cattle is carried out); D - Inspection of microclimatic environmental conditions and alarm systems (where the fitness to respond in the event of serious negative events (e.g. fire) is assessed); and E Biosecurity, for a total of 90 items. The score for each item was put into the appropriate database created by CReNBA (http://benessereruminanti.izsler.it), and then a score for each macro-area and an overall score for the farm was obtained. Certification of "Animal Welfare and Biosecurity Assessment" inspected status by CReNBA is the end of the procedure. The score ranges from 0 to 100 and identifies general welfare conditions of the herd, bracketing scores into "unclassified", "acceptable", "enhanced" and "excellent" categories.

Based on the result in the Area E, Biosecurity, the Ragusa farms were divided into two groups: group 1 consisting of 21 farms with a score between $33 \%$ and $66 \%$ (good welfare or biosecurity) and group 2 , consisting of 10 farms with a score greater than $66 \%$ (excellent biosecurity).
Blood sample collection and serum analysis. Blood samples were collected from all animals on each farm by coccygeal venipuncture into Vacuette vacuum tubes (Greiner Bio-One, Kremsmünster, Austria) with no anticoagulant additive. Blood samples were centrifuged at 3,500 rpm for $10 \mathrm{~min}$ and the obtained sera were transferred into plastic tubes. The serum samples were analysed for the detection of Mycobacterium avium subsp. paratuberculosis, Chlamydophila abortus, and Neospora caninum antibodies using an indirect ELISA and following the manufacturer's instructions (ID.Vet, Grabels, France). Each serum sample was tested in duplicate and the final results were read by a spectrophotometer (Sirio, SEAC, Florence, Italy) measuring the optical density (OD) at $450 \mathrm{~nm}$.

Data analysis. All data were expressed as mean \pm standard deviation (SD). Data obtained from the CReNBA analysis for the five inspected areas were normally distributed (Shapiro-Wilk test; $\mathrm{P}<0.05$ ). Two-way analysis of variance (ANOVA) was applied to compare the groups and the five areas. Bonferroni's test was applied for post-hoc comparison. Data obtained by the serological test were not normally distributed (Shapiro-Wilk test; P>0.05). The Mann-Whitney test was applied to compare the prevalence of antibodies to the investigated bacteria and protozoa between the two groups. Values of $\mathrm{P}<0.05$ were considered statistically significant. Statistical analysis was performed using Statistica 7.0 (Stat Soft, Tulsa, OK, USA).

\section{Results}

The mean percentages and standard deviations $( \pm \mathrm{SD})$ of animal welfare assessment areas $\mathrm{D}$, the biosecurity area $\mathrm{E}$ and the overall score in group 1 and group 2 are reported in Table 1.

The two-way ANOVA showed a significant effect of the group $(\mathrm{P}<0.0001)$ and the area of the facilities $(\mathrm{P}<0.0001)$. In particular, Bonferroni's post hoc comparison indicated a higher percentage in area $\mathrm{B}$ in group 2 than group $1(\mathrm{P}<0.05)$. The Mann-Whitney test made a higher incidence of Neospora caninum in group 1 than in group $2(\mathrm{P}=0.0008)$. The incidences of the bacteria did not show statistical differences (Table 2).

Table 1. Mean percentages and standard deviations $( \pm \mathrm{SD})$ of animal welfare assessment areas $\mathrm{A}$ and $\mathrm{D}$, the biosecurity area $\mathrm{E}$, and the overall score in group 1 and group 2

\begin{tabular}{|c|c|c|c|c|c|c|}
\hline & Area A & Area B & Area $\mathrm{C}$ & Area D & Area E & \\
\hline & $\begin{array}{c}\text { Farm } \\
\text { management } \\
\text { and personnel }\end{array}$ & $\begin{array}{c}\text { Facilities and } \\
\text { equipment }\end{array}$ & $\begin{array}{c}\text { Animal-based } \\
\text { measures }\end{array}$ & $\begin{array}{c}\text { Inspection } \\
\text { of microclimatic } \\
\text { environmental conditions } \\
\text { and alarm systems }\end{array}$ & Biosecurity & Overall score \\
\hline $\begin{array}{l}\text { Group } 1 \\
\text { Biosecurity } \\
\text { between } 33 \% \\
\text { and } 66 \% \\
\end{array}$ & $70.63 \pm 10.68^{a}$ & $62.35 \pm 13.11^{\mathrm{a}}$ & $82.30 \pm 7.15^{a}$ & $53.90 \pm 8.19^{a}$ & $50.13 \pm 8.47^{\mathrm{a}}$ & $74.91 \pm 7.29^{a}$ \\
\hline $\begin{array}{l}\text { Group } 2 \\
\text { Biosecurity } \\
\text { greater } \\
\text { than } 66 \%\end{array}$ & $76.40 \pm 11.47^{a}$ & $71.05 \pm 10.64^{b}$ & $85.69 \pm 4.86^{a}$ & $58.65 \pm 8.76^{a}$ & $71.16 \pm 5.59^{b}$ & $79.64 \pm 5.17^{\mathrm{a}}$ \\
\hline
\end{tabular}

Different superscript letters show significant differences between groups $(\mathrm{P}<0.05)$ 
Table 2. Mean percentages and standard deviations ( \pm SD) of the antibodies against Mycobacterium avium subsp. paratuberculosis, Chlamydophila abortus and Neospora caninum recorded in the animals of group 1 and group 2 farms

\begin{tabular}{lccc}
\hline & Mycobacterium avium subsp. paratuberculosis & Chlamydophila abortus & Neospora caninum \\
\hline $\begin{array}{l}\text { Group 1 } \\
\text { Biosecurity between }\end{array}$ & $4.11 \pm 5.63^{\mathrm{a}}$ & $0.89 \pm 1.37^{\mathrm{a}}$ & $23.08 \pm 12.17^{\mathrm{a}}$ \\
$\begin{array}{l}33 \% \text { and } 66 \% \\
\begin{array}{l}\text { Group 2 } \\
\text { Biosecurity greater than } \\
66 \%\end{array}\end{array}$ & $4.32 \pm 4.00^{\mathrm{a}}$ & $0.27 \pm 0.81^{\mathrm{a}}$ & $16.52 \pm 28.23^{\mathrm{b}}$ \\
\hline
\end{tabular}

Different superscript letters show significant differences between groups $(\mathrm{P}=0.0008)$

All the tested farms attained an overall animal welfare score greater than $60 \%$ (4). Among the 31 examined farms, 21 achieved an overall animal welfare score between 60 and $80 \%$ and were classified as "good". The remaining 10 achieved an overall animal welfare score $\geq 80 \%$ and were graded as "excellent" (13). In group $1,76.19 \%$ of the farms merited the evaluation "good" and $23.81 \%$ of the farms were at the "excellent" standard; in group 2, 50\% of the farms were "good" and $50 \%$ of the farms were "excellent".

\section{Discussion}

Mycobacterium avium subsp. paratuberculosis can frequently be found in dairy cattle, which results in significant economic losses because of persistent contagious infection and animal morbidity (11). This bacterium is usually introduced into herds via contaminated faeces from infected but asymptomatic cattle. Other routes, such as via contaminated faeces carried by vehicles, equipment, or visitors, grazing on contaminated pasture or drinking from contaminated water sources, or via other ruminants' faeces, are less common but may be involved. Biosecurity is therefore of paramount importance to prevent the introduction of this disease to herds (21). This study indicated a very low seroprevalence of Mycobacterium avium subsp. paratuberculosis, with no differences between the two tested groups. Bates et al. (3) reported results partially similar to ours: with a combination of pre-calving diagnostic testing to identify and remove animals that were the major source of disease spread, and simple management changes, there was a reduction in infection over a 4-year period in multiparous cows from $29.9 \%$ to $2.3 \%$.

Chlamydial infections in cattle can range from subclinical to sporadic acute disease manifestations and have an impact even at subclinical levels (1). Chlamydophila abortus has garnered significant research attention owing to its potential to cause zoonotic infection, its veterinary importance, and its economic impact (7). In contrast to the results gained by Zhou et al. (23), who found a seroprevalence of Chlamydophila abortus in Chinese cows between 3 and $35 \%$, it was evident in the Italian herds that Chlamydophila abortus in general had a low incidence with a seroprevalence of $0.89 \%$ in group 1 and of $0.27 \%$ in group 2. This is in accordance with Anstey et al. (1) who stated that animal husbandry and management systems can potentially influence infection loads in cattle. Talafha et al. (19) showed that the source of feed and water, whether newly purchased animals were isolated, whether calving took place in pens, and the abortion rate were not significantly associated with seropositivity to Chlamydophila abortus.

Neonatal mortality is a major problem in livestock operations, as are abortions, of which neosporosis is a major cause in cattle. Neosporosis has emerged as a serious disease of cattle and dogs worldwide (10). It is very difficult to eradicate this disease because dogs may wander around farms and have close contact with cattle. Therefore, the presence of dogs on a farm could potentially raise the risk of horizontal transmission (9). Our results are in accordance with a review (14) where it was highlighted that the application of managementbased control options could limit transmission. In herds with seroprevalence below $18-21 \%$ in particular, implementing suitable biosecurity measures aimed at managing host-pathogen interaction can reward the farmer and be beneficial for the control of other infectious diseases of cattle. Llano et al. (15) showed a prevalence of $28.3 \%$ for Neospora caninum in cattle which was slightly higher than what we found. In preliminary observations made in Sicily in dairy and meat cattle, Neospora caninum had an incidence rate of $88.23 \%$ on the tested farms (6).

In conclusion, we can affirm that the application of a validated checklist indicated a good percentage of farms in the investigated region to merit being graded "excellent" in animal welfare and showed this to be concomitant with a high level of biosecurity. The checklist may become a fundamental veterinarian tool for the early detection of stress conditions. In this preliminary study, the achievement of none of the evaluated farms of a welfare score so low as to grade it "poor" bears out the high quality of animal husbandry in the Ragusa region and attests to the attention that farmers pay to the welfare of the animals on their farms.

The high level of biosecurity was reflected in other checklist areas, and together all areas produced an overall percentage score for animal welfare which was good. Farms that have high levels of biosecurity may be more likely to have better management overall, which could lead to improved animal welfare. This condition could have a positive effect on the reduction of infectious diseases occurrence on the farms.

In the light of the obtained results, it would be useful to carry out further research on this topic; in particular, efforts could be made to decrease infection 
pressure in general by improving biosecurity and consequently improving infectious disease control. Mounting active surveillance, broadening producer awareness, and improving diagnostic testing and epidemiology are also goals for research which would deliver results leading to higher productivity. The future of farms will be increasingly related to the ethics they observe in production and the environment from which the farm products originate. Further studies involving a greater number of farms and provinces in the Sicilian region will be desirable in order for various expert bodies to form a reliable and above all repeatable judgment, regardless of the geographical location and size of the evaluated farms.

Conflict of Interest Statement: The authors declare that there is no conflict of interest regarding the publication of this article.

Financial Disclosure Statement: This research was funded by the Italian Ministry of Health, grant number IZSSI 12/15 RC.

Animals Rights Statement: The protocol of this study was carried out in accordance with the standards recommended by the Guide for the Care and Use of Laboratory Animals and Directive 2010/63/EU.

Acknowledgements: The authors acknowledge with their thanks to the Centro di Referenza Nazionale per il Benessere Animale (CReNBA, the Italian National Animal Welfare Reference Centre), located in Istituto Zooprofilattico Sperimentale della Lombardia ed Emilia Romagna, Brescia for the checklist data.

\section{References}

1. Anstey S.I., Quigley B.L., Polkinghorne A., Jelocnik M.: Chlamydial infection and on-farm risk factors in dairy cattle herds in South East Queensland. Aust Vet J 2019, 97, 505-508, doi: 10.1111/avj.12879.

2. Barkema H.W., von Keyserlingk M.A.G., Kastelic J.P., Lam T.J.G.M., Luby C., Roy J.-P., Le Blanc S.J., Keefe G.P., Kelton D.F.: Invited review: Changes in the dairy industry affecting dairy cattle health and welfare. J Dairy Sci 2015, 98, 7426-7445, doi: 10.3168/jds.2015-9377.

3. Bates A., O'Brien R., Liggett S., Griffin F.: Control of Mycobacterium avium subsp. paratuberculosis infection on a New Zealand pastoral dairy farm. BMC Vet Res 2019, 15, 266, doi: 10.1186/s12917-019-2014-6.

4. Bertocchi L., Fusi F.: Guidelines for the assessment of welfare and biosecurity in dairy cattle in loose housing systems. Istituto Zooprofilattico Sperimentale delle Lombardia e dell'Emilia Romagna "Bruno Ubertini", Brescia, Italy, 2014. https://archive.izsler.it/pls/izs_bs/V3_S2EW_CONSULTAZION E.mostra_pagina?id pagina $=\overline{3} 310$

5. Blokhuis H.J., Keeling L.J., Gavinelli A., Serratosa J.: Animal welfare's impact on the food chain. Trends Food Sci Tech 2008, 19, S79-S87, doi: 10.1016/j.tifs.2008.09.007.

6. Cannizzaro G.R., Napoli E., Nigro A., Gaglio G., Salina F., Iraci A.F., Antoci F.: Preliminary observations on Neospora caninum in dairy and meat cattle in Sicily. Conference poster, XVII Congresso Nazionale Societá Italiana di Diagnostica di Laboratorio Veterinario, Pacengo di Lazise (VR), Italy, 28-30 September 2016.
7. Cheong H.C., Lee C.Y.Q., Cheok Y.Y., Tan G.M.Y., Looi C.Y., Wong W.F.: Chlamydiaceae: Diseases in Primary Hosts and Zoonosis. Microorganisms 2019, 7, 146, doi: 10.3390/ microorganisms7050146.

8. Denis-Robichaud J., Kelton D.F., Bauman C.A., Barkema H.W., Keefe G.P., Dubuc J.: Biosecurity and herd health management practices on Canadian dairy farms. J Dairy Sci 2019, 102, 95369547, doi: 10.3168/jds.2018-15921.

9. Di Pietro S., De Domenico A., Rizzo M., Crinò C., Lucifora G., Giudice E.: Study on outbreak of Neospora caninum-associated abortion in dairy cows in Calabria (Southern Italy). Large Anim Rev 2015, 21, 69-72.

10. Dubey J.P., Schares G., Ortega-Mora L.M.: Epidemiology and Control of Neosporosis and Neospora caninum. Clin Microbiol Rev 2007, 20, 323-367, doi: 10.1128/CMR.00031-06.

11. Garvey M.: Mycobacterium avium subspecies paratuberculosis: A possible causative agent in human morbidity and risk to public health safety. Open Vet J 2018, 8, 172-181, doi: 10.4314/ovj.v8i2.10.

12. Garvey M.: Mycobacterium Avium Paratuberculosis: A Disease Burden on the Dairy Industry. Animals 2020, 10, 1773, doi: 10.3390/ani10101773.

13. Ginestreti J., Strano R.M., Lorenzi V., Fusi F., Angelucci A., Ferrara G., Galletti G., Bergagna S., Bolzoni G., Zanardi G., Buffoli E., Marcolini A., Bertocchi L.: Bulk tank milk quality data is unlikely to give useful information about dairy cow welfare at herd level. J Dairy Res 2020, 87, 208-211, doi: 10.1017/S0022029920000187.

14. Guido S., Katzer F., Nanjiani I., Milne E., Innes E.A.: SerologyBased Diagnostics for the Control of Bovine Neosporosis. Trends Parasitol 2016, 32, 131-143, doi: 10.1016/j.pt.2015.11.014.

15. Llano H.A.B., Guimarães M.S., Soares R.M., Polo G., da Silva A.C.: Seroprevalence and risk factors for Neospora caninum infection in cattle from the eastern Antioquia, Colombia. Vet Anim Sci 2018, 6, 69-74, doi: 10.1016/j.vas.2018.03.001.

16. Loi F., Pilo G., Franzoni G., Re R., Fusi F., Bertocchi L., Santucci U., Lorenzi V., Rolesu S., Nicolussi P.: Welfare Assessment: Correspondence Analysis of Welfare Score and Hematological and Biochemical Profiles of Dairy Cows in Sardinia, Italy. Animals 2021, 11, 854, doi: 10.3390/ani11030854.

17. Noordhuizen J.P.T.M., Metz J.H.M.: Quality control on dairy farms with emphasis on public health, food safety, animal health and welfare. Livest Prod Sci 2005, 94, 51-59, doi: 10.1016/j.livprodsci.2004.11.031.

18. Stancanelli A., Giunta R., Pilato V., Agnello S., Sabella S.: "Cognitive survey on the spread of paratuberculosis on cattle farms in central Sicily - preliminary data (in Italian) Conference Poster, XV Congresso Nazionale Societá Italiana di Diagnostica di Laboratorio Veterinario, Monreale (PA), Italy 23-25 October 2013.

19. Talafha A.Q., Ababneh M.M., Ababneh M.M., Al-Majali A.M.: Prevalence and risk factors associated with Chlamydophila abortus infection in dairy herds in Jordan. Trop Anim Health Prod 2012, 44, 1841-1846, doi: 10.1007/s11250-012-0146-9.

20. Verdugo C., Valdes M.F., Salgado M.: Herd level risk factors for Mycobacterium avium subsp. paratuberculosis infection and clinical incidence in dairy herds in Chile. Prev Vet Med 2020, 176, 104888, doi: 10.1016/j.prevetmed.2020.104888.

21. Villamil F.J., Yus E., Benavides B., Casal J., Moya S.J., Allepuz A., Diéguez F.J.: Short communication: Risk factors associated with Mycobacterium avium ssp. paratuberculosis introduction into dairy herds in Galicia, northwestern Spain. J Dairy Sci 2020, 103, 7411-7415, doi: 10.3168/jds.2020-18210.

22. Wolff C., Boqvist S., Ståhl K., Masembe C., Sternberg-Lewerin S.: Biosecurity aspects of cattle production in Western Uganda, and associations with seroprevalence of brucellosis, salmonellosis and bovine viral diarrhoea BMC Vet Res 2017, 13, 382, doi: 10.1186/s12917-017-1306-y.

23. Zhou J., Li Z., Lou Z., Fei Y.: Prevalence, Diagnosis, and Vaccination Situation of Animal Chlamydiosis in China. Front Vet Sci 2018, 5, 88, doi: 10.3389/fvets.2018.00088. 